\title{
A DINÂMICA INTERACIONAL EM SALAS DE AULA VIRTUAIS: RECURSOS DE ORALIDADE NOS MATERIAIS DIDÁTICOS ESCRITOS
}

\author{
Marlete Sandra Diedrich* \\ Patrícia da Silva Valério** \\ Karina de Almeida Rigo*** \\ Universidade de Passo Fundo \\ Instituto de Filosofia e Ciências Humanas \\ Passo Fundo, RS, Brasil
}

\begin{abstract}
Resumo: Este artigo tem como tema a dinâmica interacional em salas de aula virtuais, com enfoque nos recursos de oralidade usados nos textos escritos produzidos pelo professor. $O$ objetivo da proposta é analisar o uso de tais recursos como elementos desencadeadores do efeito de proximidade entre professor e estudantes em salas de aula virtuais, as quais se caracterizam justamente pelo distanciamento espacial e temporal dos interactantes. Para tanto, o estudo pauta-se em princípios advindos da Análise da Conversação, focalizando, em especial, os conceitos de interação, texto falado e texto escrito. Com base em tais princípios, afirma-se que a dinâmica interacional em salas de aula virtuais se estabelece e se mantém, em grande parte devido ao uso de elementos e construções linguísticas que, no texto medialmente escrito, simulam proximidade entre os interactantes. Com isso se afeta a dinâmica interacional nas referidas salas de aula em razão do efeito de proximidade produzido.
\end{abstract}

Palavras-chave: Interação. Texto falado. Texto escrito. Educação a distância.

1 CONSIDERAÇÕES INICIAIS

Este estudo assume princípios das pesquisas da Análise da Conversação, abordagem desenvolvida na vertente dos estudos etnometodológicos, os quais elegem as conversações como um lugar privilegiado de observação das organizações sociais. Nas pesquisas desenvolvidas na área da Linguística, a Análise da Conversação se volta para o caráter pragmático da atividade linguística característica do cotidiano da sociedade. Neste artigo, focalizamos uma atividade linguística específica: aquela que caracteriza a interação entre professor e aluno em salas de aula virtuais, as quais se estabelecem com o auxílio de um Ambiente Virtual de Aprendizagem (AVA), ou seja, uma plataforma digital de ensino.

\footnotetext{
* Docente do Programa de Pós-graduação em Letras. Doutora em Estudos da Linguagem - Teorias do Texto e do Discurso (UFRGS). E-mail: marlete@upf.br

** Docente do Programa de Pós-graduação em Letras. Doutora em Linguística Aplicada (UNISINOS). Email: patriciav@upf.br
}

*** Mestranda no Programa de Pós-graduação em Letras. E-mail: karinarigo@gmail.com 
Entendemos que as salas de aula virtuais necessitam de uma atmosfera interacional específica, a qual pode ser obtida por meio de determinados recursos interacionais marcados linguisticamente no discurso produzido pelos interactantes. Essa realidade específica da Educação a Distância traz à discussão o seguinte aspecto: o uso de recursos da oralidade na modalidade escrita. Acerca desse aspecto, faz-se necessário alertar para um equívoco muito comum em nosso meio acadêmico: não se trata de eleger determinadas marcas de oralidade e verificar sua ocorrência em textos escritos. Isso porque, com base nas análises de Gumperz (1982) acerca da identidade social, sabemos que os recursos de interação devem ser analisados com base nos efeitos que produzem na vida das pessoas. No caso de nossa investigação, podemos afirmar que tais recursos precisam ser analisados a partir dos efeitos que produzem na relação entre professor e estudantes em salas de aula virtuais.

Acreditamos, portanto, que o professor, nessas salas de aula virtuais, ao produzir seu material didático a ser apresentado por meio de um texto escrito aos seus estudantes, recorre ao uso de elementos e construções discursivas que evocam a oralidade a fim de produzir um efeito de proximidade em relação ao estudante, uma vez que esse efeito é considerado necessário para a efetiva relação interativa entre os participantes da aula em questão. Sendo assim, o tex to produzido para esses materiais assumiria uma característica particular: conforme Marcuschi (2001), seria um texto escrito apenas do ponto de vista do meio, uma vez que, conceptualmente, trata-se de um texto falado.

Para entender tal particularidade, como já anunciamos, é fundamental que seja analisada a relação entre os interactantes no discurso, a fim de que, de fato, tenhamos uma visão aproximada dos efeitos produzidos na relação interacional derivados do uso dos recursos de oralidade no texto escrito. Na sequência, ocupamo-nos de conceitos que melhor definem as diferenças existentes entre o texto marcado por traços de oralidade e o texto prototipicamente escrito, sempre observando a interação que os derivou.

\section{TEXTO ESCRITO MARCADO PELA ORALIDADE: A CONSTITUIÇÃO DE UM SIMULACRO DE PROXIMIDADE}

Para melhor entendermos o que estamos propondo sobre o texto escrito marcado pela oralidade, é importante lembrarmos os estudos de Marcuschi (2001), os quais definem a oralidade como uma prática social, e a fala como uma modalidade de uso da língua, da qual resulta uma produção textual discursiva oral. Essa produção textual difere daquela derivada da escrita em função de dois aspectos em especial: a natureza explicitamente interacional e o caráter essencialmente processual do texto falado.

$\mathrm{Na}$ verdade, sabemos que qualquer texto é produzido por força de uma interação, seja ele escrito ou falado. No entanto, o tex to falado é gerado, em princípio, numa situação em que os interlocutores se encontram face a face, condição que possibilita e até impulsiona uma ação colaborativa dos interlocutores na produção deste texto, na medida em que vão, na alternância de turnos, abordando tópicos tematicamente centrados. Quanto ao outro aspecto, o texto falado é concebido como um processo. Ou seja, com base em estudos de Rath (1979, apud HILGERT, 2000), entendemos que o produto texto falado consiste em grande parte nas marcas de sua própria produção, uma vez que ele é resultante de dois procedimentos simultâneos: o planejamento e a formulação. 
O falante assume o turno conversacional e planeja seu texto enquanto o vai formulando, na relação com o outro. A simultaneidade com que se realizam as atividades de planejamento e de formulação é responsável por uma configuração particular: o texto falado é, assim, marcado por reformulações, pausas, alongamentos, entre outros. São essas marcas que distinguem o texto falado do texto escrito, uma vez que, na construção do texto escrito prototípico, as marcas reveladoras de sua formulação são apagadas.

Encontramos em Hilgert uma descrição de texto falado que melhor nos auxilia a entender essa distinção:

\begin{abstract}
Um texto conceptualmente falado prototípico se caracterizaria, do ponto de vista das condições de comunicação, por um alto grau de privacidade, de intimidade, de envolvimento referencial, de cooperação, de dialogicidade, de espontaneidade entre os interlocutores e, também, por um destacado grau de dependência situacional e interacional das atividades de comunicação, além de um baixo grau de centração temática. Do ponto de vista das estratégias de formulação, esse mesmo texto falado seria fortemente marcado por fatores não lingüísticos, teria pouco ou nenhum planejamento prévio, fato que lhe daria um caráter essencialmente "processual e provisório", apresentaria uma estruturação sintática "extensiva, linear e agregativa' e uma densidade informacional diluída. (HILGERT, 2000, p. 19).
\end{abstract}

É importante frisarmos que essas características não colocam o texto falado em oposição estrita ao texto escrito. Na verdade, o que os estudos da área propõem é que os textos possam ser vistos como falados ou escritos em maior ou menor grau, numa espécie de continuum (MARCUSCHI, 2001). Por essa razão, um texto pode ser, do ponto de vista de sua realização, considerado falado, já que se manifesta por meio da realização fonética, mas pode apresentar, do ponto de vista conceptual, características próprias do texto escrito. Essa característica já foi abordada em Diedrich e Valério (2012), quando foram analisadas as interações nas redes sociais. A mesma questão se faz presente agora, quando nos voltamos para a sala de aula virtual, no entanto, nosso interesse agora recai sobre o texto dos materiais didáticos e a dinâmica interacional que deriva da relação do professor com os estudantes a partir do uso desses textos.

Para tratarmos da dinâmica interacional em foco, buscamos o conceito de interação na teoria de Bakhtin e seu Círculo ${ }^{1}$. Tal conceito está relacionado àquele de enunciação, a qual é definida como o produto da interação de dois indivíduos (BAKHTIN, 2010). Para o autor, a palavra, entendida aqui na sua acepção ampla, isto é, como discurso, comporta duas faces, pois ela sempre procede de alguém e se dirige a alguém. Por essa razão, "a palavra é uma espécie de ponte lançada entre mim e os outros. Se ela se apóia sobre mim numa extremidade, na outra apóia-se sobre o meu interlocutor." (BAKHTIN, 2010, p. 117). $\mathrm{Na}$ interação entre o professor e os estudantes de salas de aula virtuais, a reciprocidade do comportamento se dá a conhecer pelo discurso produzido, marcado

\footnotetext{
${ }^{1}$ Conforme Faraco (2003), o Círculo de Bakhtin é uma denominação atribuída a um grupo multidisciplinar constituído na URSS no início do século XX, composto por jovens intelectuais das mais diferentes áreas, dentre os quais os representantes mais célebres são Mikhail M. Bakhtin, Pavel N. Medvedev e Valentin N. Voloshinov. Reconhecemos que o texto a que fizemos referência neste trabalho integra uma das obras cuja autoria é contestada, porém não entraremos no labirinto da polêmica que envolve a autoria, uma vez que há farta literatura sobre o tema. O leitor interessado nessa discussão poderá aprofundar a leitura em Faraco, 2003.
} 
pelos conhecimentos que partilham e por fatores socioculturais, expressos na maneira como produzem o seu discurso e conduzem o diálogo. Acerca dessa questão, vale lembrar que nas salas de aula virtuais os interactantes não se encontram necessariamente on-line, não havendo, portanto, simultaneidade na ação interativa.

Justamente por essa condição de produção do discurso, faz-se necessário que o professor lance mão de recursos linguísticos que possam dar conta da aproximação com os estudantes, criando o que estamos chamando aqui, à semelhança do que outros autores já o fizeram (HILGERT, 2011), de simulacro, uma vez que cria um efeito de proximidade entre enunciador e enunciatário por meio da mobilização de recursos que levam o texto medialmente escrito pelo professor se assemelhar ao texto conceptualmente falado, característico das conversações. Ou seja, o texto de cunho didático produzido pelo professor e disponibilizado na plataforma digital será acessado pelos estudantes em outros espaços e em outros momentos, diferentemente do que ocorre com o texto falado conversacional, em cujo processo de produção e recepção os interactantes se encontram face a face. Entendemos, no entanto, que o professor tem condições de simular uma interação face a face com os estudantes, marcando o texto produzido por elementos que possibilitam a criação de uma atmosfera interacional, no intuito de produzir um efeito de proximidade com os estudantes.

Estaríamos, assim, frente a um texto escrito do ponto de vista do meio de sua produção; no entanto, esse texto apresentaria marcas de uma interação face a face, aproximando-o, dessa forma, conceptualmente, do texto falado. Silva (2015) chama isso de "naturalidade elaborada", uma vez que ela foi construída pelo professor que organizou seus materiais didáticos com o intuito de criar o efeito de proximidade em relação aos estudantes. Também por isso é fundamental que pensemos na recepção do texto pelos estudantes, os quais deverão ser capazes de resgatar tais elementos interacionais a fim de que se cumpra o propósito interacional.

Segundo Hilgert (2014, p. 154), "Nas práticas sociais, o uso da linguagem - seja pela fala ou por escrito, seja com interlocutores próximos ou distantes entre si - é sempre uma instância de enunciação, que realiza a interação entre enunciador e enunciatário". Por essa razão, enunciador e enunciatário estão sempre em relação, realizando-se entre eles a coenunciação, uma vez que o enunciatário, pressuposto pelo enunciador e, portanto, determinante nas escolhas discursivas, é também produtor do discurso. $\mathrm{Na}$ situação específica das salas de aula virtuais, o professor que organiza seu material didático mobiliza elementos responsáveis por uma dinâmica interacional que prevê a participação dos estudantes a partir de um determinado modo de dizer e de fazer, antecipando no discurso o dizer do outro. É dessa produção de discursos, portanto, que decorre o sentido mobilizado na interação, altamente dependente dos recursos usados pelo professor na tentativa de construir uma proposta de compreensão. Tal proposta é recebida pelo enunciatário e somente com seu fazer interpretativo em relação ao dizer do enunciador é que podemos perceber a totalidade do que foi proposto. Por essa razão, elegemos a dinâmica interacional como realidade nas interações em questão neste artigo: há uma dinâmica que envolve o dizer-fazer tanto do enunciador quanto do enunciatário e que se marca no discurso produzido. 
Na sequência, ocupamo-nos de dois materiais didáticos produzidos por professores de salas de aula virtuais, no intuito de observar a construção do texto na busca de elementos interacionais que denotem um investimento do professor na busca de criar um simulacro conversacional na dinâmica interacional com os estudantes.

\section{ANÁLISE DOS MATERIAIS DIDÁTICOS DE SALAS DE AULA VIRTUAIS}

Os materiais aqui analisados foram produzidos por professores da disciplina de Leitura e Produção de Textos na modalidade semipresencial, da área de Língua Portuguesa, oferecida para diversos cursos de graduação da Universidade de Passo Fundo, com o uso da plataforma Moodle. Moodle é uma sigla usada para Modular Object Oriented Distance Learning: um sistema de gerenciamento para criação de curso on-line. Esses sistemas são também chamados de Ambientes Virtuais de Aprendizagem (AVA) ou de Learning Management System (LMS). A plataforma vem sendo utilizada não só como ambiente de suporte à Educação a Distância, mas também como apoio a cursos presenciais, formação de grupos de estudo, atualização de professores.

Leitura e Produção de Textos Semipresencial é uma disciplina de 60 horas, as quais se distribuem ao longo do semestre e das quais $80 \%$ ocorrem a distância. Voltamo-nos, portanto, à análise dos textos que caracterizam dois materiais didáticos disponibilizados na plataforma Moodle para acesso e leitura dos estudantes da disciplina. Em nossa análise, buscamos, como já deixamos claro, recursos de oralidade usados nos textos escritos produzidos pelo professor os quais possam estar relacionados ao desencadeamento do efeito de proximidade entre professor e estudantes.

O Material didático 1 faz parte da configuração de uma ferramenta conhecida na plataforma em questão como livro. O livro é uma ferramenta que permite ao professor disponibilizar material verbal e não verbal em formato de um único arquivo, o qual se assemelha, de fato, a um livro físico, com configuração de índice e páginas, inclusive. Em geral, é usado pelo professor para o tratamento de questões teóricas mais densas, que exigem um tempo de leitura maior por parte dos estudantes, os quais poderão acessar o conteúdo disponibilizado, no caso específico desta disciplina, ao longo de uma semana, para, a partir dele, realizar determinadas atividades a serem enviadas por meio de outras ferramentas digitais que compõem o ambiente virtual de aprendizagem.

O texto produzido para compor o livro Como resumir tem por objetivo principal fornecer determinadas informações aos estudantes sobre a atividade acadêmica de resumir um texto. É de autoria do próprio professor da disciplina, conforme vemos a seguir:

\section{Material didático 1: Livro Como resumir}

Como resumir

Inicialmente, vamos definir, prezado graduando, o que é o resumo. O resumo é uma prática discursiva desenvolvida com o objetivo de apresentar as principais ideias de um texto, mantendo-se fiel a ele. No cotidiano acadêmico, em geral, fazemos resumos a pedido dos 
professores para comprovar leituras realizadas nas diferentes disciplinas ou para anunciar trabalhos a serem apresentados, como é o caso do resumo de um artigo científico. Em qualquer uma dessas situações, de qualquer forma, o trabalho exige um esforço cognitivo, já que só podemos resumir o que de fato compreendemos. Sendo assim, antes de proceder a qualquer atividade de resumo, precisamos ler o texto a ser resumido atentamente.

E depois, o que fazer? Esta deve ser a pergunta que você está se fazendo, e que eu tentarei responder. Feita a leitura atenta do texto, passamos a destacar a ideia central de cada parágrafo: sublinhe-a. Não sei se você já sabia disso, mas parágrafo não é apenas uma questão de organização espacial do texto no papel, trata-se de uma questão de organização mental das ideias que formam o todo organizado que é o texto. Procure, neste momento, avaliar o que é ideia central e o que é ideia secundária na composição do texto.

Com esse cuidado, você deixará de lado os exemplos e elementos figurativos que acompanham o texto, já que o importante no resumo são os argumentos. Estando destacadas as ideias centrais, você precisa investir agora na redação do seu resumo. Lembre-se de que ele não pode parecer uma "colcha de retalhos", pelo contrário, as ideias precisam aparecer em sequência lógica, muito bem concatenadas entre si.

Como garantir essa relação entre as partes? Para isso, usamos os nexos de ligação, representados por conjunções, preposições, advérbios e outras expressões que garantem ao texto o que chamamos de coesão. Por essa razão, figuram num resumo expressões como: além disso, entretanto, em segundo lugar, primeiramente, então...

É possível percebermos na construção do texto em questão um investimento do professor em marcar o discurso por elementos interacionais típicos da oralidade, os quais buscam aproximá-lo dos estudantes, na tentativa de simular, de fato, uma conversação. Isso pode ser verificado nos diferentes recursos que buscam organizar a sequência textual, anunciando o que ocorrerá ao longo da formulação do texto: "Inicialmente, vamos definir, prezado graduando, o que é o resumo", 'E depois, o que fazer?' “Como garantir essa relação entre as partes?". Esse recurso certamente se encarrega de organizar o fluxo informacional ao longo do texto e objetiva prender a atenção do leitor. No caso de este mesmo texto ser produzido oralmente em situação presencial de sala de aula, certamente haveria condições no aqui e no agora da interação de se lançar mão de outros recursos para prender a atenção dos estudantes, como a entonação da voz, a gestualidade, entre outros. Na ausência de tal possibilidade, cabe ao professor valer-se dos elementos citados anteriormente para buscar uma maior proximidade com os estudantes, uma vez que esses, no momento em que acessarem o texto a ser lido, poderão resgatar parte das condições de produção do texto.

Nesse sentido, sublinhamos a importância do aspecto temporal no discurso. Compreendemos discurso a partir de Benveniste (1995, p. 267) como "toda enunciação que suponha um locutor e um ouvinte e tenha a intenção de influenciar, de algum modo, o outro. [...] a diversidade dos discursos orais ${ }^{2}$ de qualquer natureza e de qualquer nível, da conversa trivial à oração mais ornamentada.”. Sendo assim, a mobilização do aspecto

\footnotetext{
${ }^{2}$ É importante consultar Benveniste (1995, p. 267) sobre a distinção entre narrativa histórica e discurso, em texto no qual rechaça qualquer associação simplista da primeira modalidade à língua escrita e da segunda à língua falada. Embora a enunciação histórica seja restrita à língua escrita, o discurso pode manifestar-se tanto na escrita quanto na fala: "na prática, passa-se de um ao outro instantaneamente. [...] O próprio da linguagem consiste em permitir essas transferências instantâneas".
} 
temporal no discurso possibilita ao professor, no ato de produção de seu texto, a antecipação de questões que virão a surgir no momento de leitura do texto pelos estudantes, o que se caracteriza por um novo investimento no simulacro conversacional em questão: apesar de os interactantes não estarem compartilhando do mesmo tempo e espaço, o texto revela marcas, em sua produção, do momento futuro de sua recepção, já previsto pelo professor enunciador no tempo de produção do discurso: "Esta deve ser a pergunta que você está se fazendo, e que eu tentarei responder." Conforme Diedrich (2017, p. 509), "Essa relação entre $e u$ e $t u$, portanto, é viva e imediata, pois não há locutor sem o outro da enunciação; não há emissão sem percepção." No contexto em questão, isso é possível em função da mobilização de construções típicas da oralidade, as quais criam uma simulação de simultaneidade do ato de produção e de recepção do texto, como denuncia o uso do vocativo "você", do tempo verbal presente associado à forma do gerúndio, assim como a marca discursiva "eu”, a qual também contribui para criar efeito de proximidade típico da oralidade, apesar de se tratar de um texto produzido em meio escrito. Até mesmo a referência a uma ação futura: "eu tentarei responder" diz respeito a uma reflexão acerca da construção do texto, o que pode ser entendido como marca de formulação no produto final apresentado ao leitor, o que, em geral, num texto escrito, é apagado ou construído de forma diferente. Aqui, ao contrário, mantém-se, garantindo ao tu a possibilidade de acessar o momento de formulação do texto, o qual ficou no passado, mas se revela virtualmente possível de ser resgatado e revivido, no discurso, pelo estudante que lê o material didático.

Observamos que o texto estabelece uma temporalidade que visa conduzir o trabalho a ser desenvolvido pelo aluno. O discurso instaura um agora, o momento da enunciação. É sabido que, dentre as formas reveladoras da experiência subjetiva da linguagem, as que exprimem tempo são as mais ricas e, por isso mesmo, complexas. Essas formas são percebidas de modo mais explícito em algumas classes de palavras, como dêiticos, pronomes demonstrativos, verbos no imperativo. No entanto, elas não são as únicas e nem atuam sozinhas no discurso, pois há um tempo específico do discurso, o tempo linguístico, que está ligado ao exercício da fala, organiza-se e define-se como função do discurso e tem seu centro no presente da instância de fala: "cada vez que um locutor emprega a forma gramatical do 'presente' (ou uma forma equivalente), ele situa o acontecimento como contemporâneo da instância do discurso que o menciona" (BENVENISTE, 1989, p. 74).

Assim, o momento da enunciação exerce sempre o papel de um eixo responsável pela ordenação do tempo, de um tempo específico da interação texto/leitor dada a propriedade original da linguagem: o fato de este presente ser reinventado a cada vez que um homem fala, porque esse momento é novo e ainda não foi vivido. Esse momento será revivido a cada vez que o leitor acessar o texto e enunciar. Essa realidade enunciativa leva, segundo Hilgert (2015), o enunciador a projetar no enunciado, de forma calculada ou não, suas escolhas, movido pelas circunstâncias da comunicação em curso e por seus propósitos em relação a ela. No caso específico que analisamos, essas escolhas revelam uma circunstância de comunicação na qual enunciador e enunciatário encontram-se em tempos e espaços diferentes, mas cujo propósito é justamente produzir, pelo discurso, um efeito de proximidade entre eles. Segundo Hilgert: "Como a proximidade determina a 
natureza das interações face a face, isto é, das conversas, o efeito de proximidade no texto escrito vai-se produzir no uso de recursos da linguagem que evoquem a fala das interações cotidianas e informais." (HILGERT, 2011, p. 179).

O autor aprofunda a questão, mostrando que a escolha de tais recursos não é aleatória, ela é configurada a partir da relação pelo enunciador e enunciatário na situação interativa. Por essa razão, não estamos aqui propondo a análise de um elenco de determinados recursos linguísticos aprioristicamente definidos, mas ocupamo-nos de discutir a dinâmica interacional mobilizada a cada situação de comunicação proposta a partir da relação professor e estudante.

Nossa análise se volta, na sequência, ao Material didático 2, um material didático bastante comum em salas de aula virtuais, conhecido como uma "atividade" no Ambiente Virtual de Aprendizagem Moodle: o fórum.

\title{
Material didático 2: Atividade de Fórum
}

\begin{abstract}
A partir do que lemos no livro A especificidade do texto literário e das obras literárias a que você teve acesso, em especial, Morte e Vida Severina (animação) e Vidas Secas, discuta comigo, com a monitora e com seus colegas:

Que dramas sociais foram focalizados nessas obras?

Você conhece outras obras literárias, inclusive em produções fílmicas, que também abordam esse tipo de problema social? Poderia nos dar sugestões de leitura?

Destaque momentos ou segmentos das obras lidas que chamaram sua atenção pelos arranjos linguísticos e comente o sentido mobilizado nesta situação.

Mas, cuidado! Para obtermos sucesso nesta atividade de fórum, não basta responder a essas questões como se fosse um questionário. Você precisa conversar com os demais participantes, ler o que eles postaram e inserir seus comentários a partir do que leu no comentário deles. Por isso, organizei o fórum em pequenos grupos de 5 pessoas. Assim, você poderá ler com atenção as postagens dos colegas e interagir com eles. Estou bem curiosa para ler suas postagens. Participe!
\end{abstract}

Acerca da atividade "fórum", Sturm (2015) afirma:

Essa ferramenta destaca o encadeamento das discussões, além de identificar os autores das mensagens, por meio de suas fotos inseridas no perfil de cada participante. Isso parece gerar um sentimento de aproximação e de vínculo entre os envolvidos, semelhante a um chat ou a uma rede social, como o facebook, por exemplo, fato positivo que aproxima as ações acadêmicas e formativas da realidade dos estagiários, ampliando as possibilidades de que eles utilizem essas ferramentas em seu dia a dia, como futuros professores. (STURM, 2015, p. 280).

A atividade fórum, neste caso, foi pensada e organizada pelo professor no intuito de levar os estudantes a interagirem entre eles e com o professor a partir de um tópico discursivo estabelecido na conversação. $O$ fórum tem um papel especial nas salas de aula virtuais em geral, porque representa o momento do debate na sala de aula, no qual cada interactante deverá se posicionar em relação ao dizer do outro. Para tanto, é necessário, obviamente, que o estudante não apenas poste seu dizer no fórum, mas construa-o em relação ao dizer do outro. Não basta o sujeito estar informado, faz-se necessário que ele produza um novo dizer a partir desta informação, numa rede colaborativa que se forma, 
no caso aqui focado, no fórum. Para tanto, o professor, ao apresentar a atividade e convocar o estudante a participar, lança mão de determinados recursos que chamam nossa atenção para o tema em questão.

Inicialmente, percebemos que há o uso de verbos no modo imperativo que buscam comandar a ação dos estudantes, promovendo a orientação para o ato comunicativo esperado pelo professor. Trata-se, certamente, de uma característica das atividades de qualquer professor em situação de ensino no momento em que apresenta uma atividade a ser realizada pelos estudantes, como ocorre, por exemplo, no livro didático. No entanto, no encaminhamento específico desta atividade na sala virtual, o professor vê a necessidade de explicitar como se organiza o fórum, a fim de procurar garantir o caráter interacional dessa atividade, por isso, chega a definir o que é o fórum e o que ele exige dos participantes para se caracterizar como tal. Além disso, marca o encaminhamento da atividade com perguntas condutoras a serem respondidas no decorrer da atividade. Certamente o uso de perguntas como Que dramas sociais foram focalizados nessas obras? Você conhece outras obras literárias, inclusive em produções fílmicas, que também abordam esse tipo de problema social? Poderia nos dar sugestões de leitura? contribui para aproximar o professor que enuncia do estudante enunciatário, o qual é convocado, por meio dos elementos interacionais expressos em forma de pergunta a participar da interação, assumindo o espaço de dizer a ele reservado.

O fórum, assim, a ser estabelecido, parte de um tópico dado pelo professor, mas deve se renovar em sua realização, uma vez que dependerá, em grande parte, das inserções efetuadas pelos interactantes e dos novos tópicos que poderão derivar dessa relação interacional, o que o aproxima, em grande parte, de um texto falado cuja formulação e planejamento se dão a conhecer no próprio surgir do texto. Não analisamos aqui o desenvolvimento do fórum, tarefa que consideramos importante e que pode merecer um novo estudo, no entanto, podemos afirmar, desde já, que, em sua realização, o papel do professor acaba por ser de moderador da discussão, como forma de garantir a abordagem do tópico discursivo dado e o aprofundamento das discussões.

\section{CONSIDERAÇÕES FINAIS}

Certamente, não é nosso objetivo principal neste artigo orientar professores em suas ações pedagógicas na educação a distância. No entanto, percebemos, com a análise dos recursos desencadeadores do efeito de proximidade entre professor e estudantes em salas de aula virtuais, que a dinâmica interacional nessas salas de aula é altamente dependente do caráter interacional promovido pelo professor no discurso que caracteriza suas inserções didáticas nas plataformas digitais de ensino e aprendizagem.

Essa constatação nos leva a afirmar que muito já alcançamos no meio educacional em termos de superação de mitos e equívocos em relação ao texto falado e ao escrito, abandonando dicotomias estritas, aproximando olhares e teorias; no entanto, é necessário ainda que nos voltemos para os efeitos produzidos pela mobilização de estratégias de construção dos textos característicos da interações entre professor e aluno, uma vez que consideramos tais efeitos extremamente importantes para o desenvolvimento das atividades de ensino e de aprendizagem. 
BAKHTIN, M. (V. N. VOLOCHÍNOV). Marxismo e filosofia da linguagem: problemas fundamentais do método sociológico na ciência da linguagem. Trad. Michel Lahud e Yara Frateschi Vieira. 14. ed. São Paulo: Hucitec, 2010.

BENVENISTE, É. Problemas de Linguística Geral II. Campinas, SP: Pontes Editores, 1989. Problemas de Linguística Geral I. Campinas, SP: Pontes Editores, 1995.

DIEDRICH, M. S.; VALÉRIO, P. O uso das tecnologias de informação e comunicação no ensino de língua e suas implicações. Domínios de Lingu@gem, Uberlândia, v. 6, n. 2, p. 10-18, dez. 2012. Disponível em: <http://www.seer.ufu.br/index.php/dominiosdelinguagem/article/view/17932>. Acesso em: 26 ago. 2016.

DIEDRICH, M. S. A interpretância da língua em relação às funções inter-humanas do discurso na aquisição da linguagem via aspecto vocal da enunciação. DELTA, São Paulo, v. 33, n. 2, p. 497-517, ago. 2017. Disponível em:

<http://www.scielo.br/scielo.php?script=sci_arttext\&pid=S010244502017000200497\&lng=en\&nrm=iso> . Acesso em: 27 ago. 2017.

FARACO, C.A. Linguagem e diálogo: as ideias linguísticas do Círculo de Bakhtin. 2. ed. Curitiba: Criar Edições, 2003.

GUMPERZ, J.J. Discourse Strategies. Cambridge: Cambridge University Press, 1982.

HILGERT, J. G. A construção do texto "falado" por escrito: a conversação na internet. In: PRETI, D. (Org.). Fala e escrita em questão. São Paulo: Humanitas, 2000. p. 17-55.

. A oralidade em textos escritos: reflexões à luz de uma teoria de texto. Calidoscópio, São Leopoldo, v. 9, n. 3, p. 171-179, set./dez. 2011. Disponível em: <http://revistas.unisinos.br/index.php/calidoscopio/article/viewFile/cld.2011.93.01/551>. Acesso em: 30 ago. 2016

A emergência da compreensão na conversa, mostrada no trabalho colaborativo de otimização de enunciados. Todas as Letras, São Paulo, v. 16, n. 1, p. 151-167, maio 2014. Disponível em: <http://dx.doi.org/10.15529/1980-6914/letras.v16n1p151-167>. Acesso em: 20 ago. 2016.

Fundamentos para o estudo da oralidade na escrita. Filologia e Linguística Portuguesa, São Paulo, v. 17, n. 1, p. 57-73, jan./jun. 2015.

MARCUSCHI, L. A. Da fala para a escrita: atividades de retextualização. São Paulo: Cortez, 2001. MOODLE LIVRE. O que é o moodle? Disponível em: <https://www.moodlelivre.com.br/tutoriais-edicas/974-o-que-e-moodle>. Acesso em: 20 ago. 2016.

SILVA, L. A. Conversação e oralidade em textos escritos. Filologia e Linguística Portuguesa, São Paulo, v. 17, n. 1, p. 131-155, jan./jun. 2015.

STURM, L. Web-processfolio como recurso de aprendizagem e instrumento de avaliação na formação de professores de língua estrangeira. In: ROTTAVA, L.; BARCELLOS, P. da S. C.; DUTRA, E. de O.; PINHO, I. C. Reflexões em Linguística Aplicada: a formação de professores de línguas e a prática em sala de aula - caminhos e expectativas. Campinas, SP: Pontes, 2015.

Recebido em: 03/02/17. Aprovado em: 09/08/17.

Title: Interactional dynamics in virtual classrooms: orality resources in written teachinglearning materials

Authors: Marlete Sandra Diedrich; Patrícia da Silva Valério; Karina de Almeida Rigo

Abstract: The subject of this article is the interactional dynamics in virtual classrooms, with emphasis on oral resources used in written texts produced by the teacher. The objective of this discussion is to analyze the use of those resources as triggering elements on the effect of proximity between teacher and student in virtual classrooms, which are precisely known by the spatiotemporal distance among the interactants. Therefore, the research is based on the principles of Conversation Analysis, focusing specially in the concepts of interaction, spoken and written texts. Based on such principles, we affirmed the interactional dynamics in virtual classrooms is established and sustained most by the usage of elements and linguistic 
constructions that, in the medially written text, simulates the proximity among the interactants. Thereby, the interactional dynamics is affected in virtual classrooms by the produced effect of proximity.

Keywords: Interaction. Spoken text. Written text. Distance education.

Título: La dinámica de interacción en clases virtuales: recursos de oralidade en materiales didácticos escritos

Autoras: Marlete Sandra Diedrich; Patrícia da Silva Valério; Karina de Almeida Rigo

Resumen: Este artículo tiene como tema la dinámica de interacción en clases virtuales, con enfoque en los recursos de oralidad usados en los textos escritos producidos por el profesor. El objetivo de la propuesta es analizar el uso de tales recursos cómo elementos desencadenadores del efecto de proximidad entre profesor y estudiantes en clases virtuales, las cuales se caracterizan justamente por el alejamiento espacial y temporal de los que interaccionan. Para ello, el estudio se basa en principios que vienen del Análisis de la Conversación, focalizando especialmente los conceptos de interacción, texto hablado y texto escrito. Con base en tales principios, se afirme que la dinámica de interacción en clases virtuales se establece y se mantienen principalmente en razón del uso de elementos y construcciones lingüísticas que, en el texto medialmente escrito, simulan proximidad entre los que interaccionan. Con ello, afecta la dinámica de interacción en las referidas clases por medio del efecto producido.

Palabras-clave: Interacción. Texto hablado. Texto escrito. Educación a distancia.

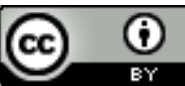

Este texto está licenciado com uma Licença Creative Commons Atribuição 4.0 Internacional.

DIEDRICH, Marlete Sandra; VALÉRIO, Patrícia da Silva; RIGO, Karina de Almeida. A dinâmica interacional em salas de aula virtuais: recursos de oralidade nos materiais didáticos escritos. Linguagem em (Dis)curso LemD, Tubarão, SC, v. 17, n. 3, p. 349-359, set./dez. 2017. 